\title{
FINAL REPORT FOR PROJECT
}

\section{Plasma Processing of Advanced Materials}

DOE Grant No. DE-FG02-85ER13433 Ao15

\author{
submitted to \\ Dr. T. Fitzsimmons, DOE-BES \\ by \\ Joachim Heberlein, Emil Pfender and Uwe Kortshagen \\ Department of Mechanical Engineering \\ University of Minnesota
}

February 2005 


\section{Plasma Processing of Advanced Materials}

\section{Project Overview}

This project has the overall objective of improving our understanding of the influences of process parameters on the properties of advanced superhard materials. The focus was on high rate deposition processes using thermal plasmas and atmospheric pressure glow discharges, and the emphasis on superhard materials was chosen because of the potential impact of such materials on industrial energy use and on the environment. In addition, the development of suitable diagnostic techniques was pursued.

The project was divided into four tasks:

(1) Deposition of superhard boron containing films using a supersonic plasma jet reactor (SPJR), and the characterization of the deposition process.

(2) Deposition of superhard nanocomposite films in the silicon-nitrogen-carbon system using the triple torch plasma reactor (TTPR), and the characterization of the deposition process.

(3) Deposition of films consisting of carbon nanotubes using an atmospheric pressure glow discharge reactor.

(4) Adapting the Thomson scattering method for characterization of atmospheric pressure non-uniform plasmas with steep spatial gradients and temporal fluctuations.

In the first two years of the project, work proceeded in parallel on tasks 1, 2 and 4 , while in the remaining two years (including the 1 year extension) research was performed on tasks 1, 2 and 3. Presently, work is continuing on tasks 1 and 2 supported by other sources, and we expect several interesting results to be published within this year.

\section{Task 1: Supersonic plasma jet deposition of boron containing superhard} films

The supersonic plasma jet reactor (SPJR) was used in the deposition of boron nitride films. Various experimental parameters were examined concerning their role in cubic boron nitride (cBN) deposition, including plasma composition, torch power, and substrate bias. The results are summarized as follows.

When examining the role of plasma chemistry in boron nitride deposition, the influence of hydrogen in the $\mathrm{Ar}-\mathrm{BF}_{3}-\mathrm{N}_{2}-\mathrm{H}_{2}$ system used in deposition was investigated. Thermodynamic calculations by Kalss et al [1] indicate that in this chemical system, hydrogen reacts with free fluorine to form $\mathrm{HF}$ according to the reaction

$$
2 \mathrm{BF}_{3}+\mathrm{N}_{2}+3 \mathrm{H}_{2} \longrightarrow 2 \mathrm{BN}+6 \mathrm{HF}
$$

thereby controlling the amount of film etching from atomic fluorine. Hydrogen played an important role in BN deposition in the SPJR, as greater amounts of hydrogen clearly lead to higher BN deposition rates, while lesser amounts of hydrogen corresponded to greater amounts of etching of the substrate and film, and therefore less BN deposition [2]. This proposed role of hydrogen in film etching was also examined through a qualitative optical emission spectroscopy study. Figure la shows a two-dimensional plot of the relative intensity of the $\mathrm{H}_{\alpha}$ emission line near the substrate, while Figure 1b shows Fourier transform infrared (FTIR) spectra of the film at two positions on the substrate. Considering 
the proposed role of hydrogen, the BN film distribution indicated in Figure $1 \mathrm{~b}$ is consistent with the hydrogen distribution near the substrate shown in Figure 1a, where the region of higher hydrogen concentration in the gas phase (lower portion of the image) corresponds to the FTIR trace indicating higher amounts of $\mathrm{BN}$, obtained from the lower portion of the substrate.
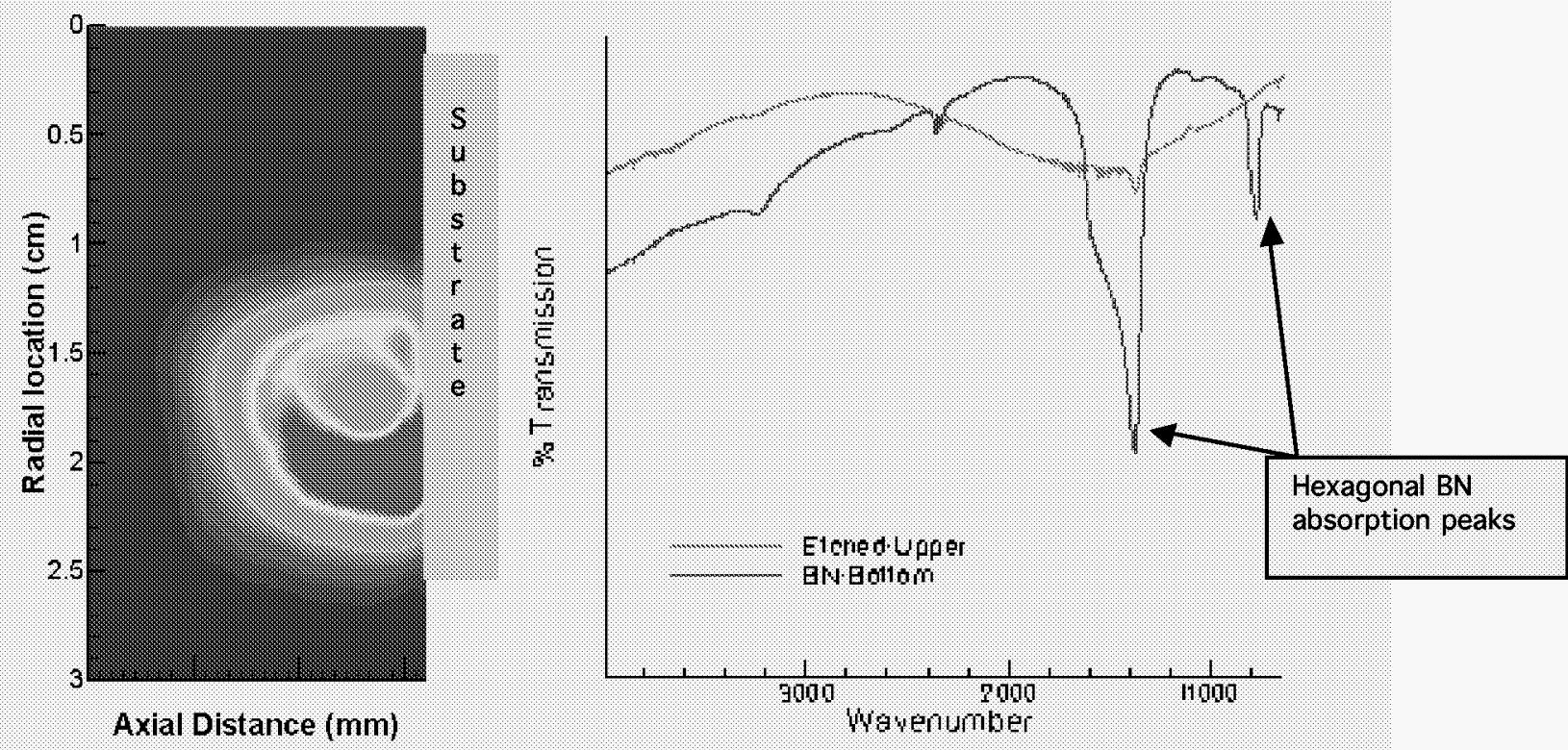

Figure 1a: Distribution of Ha emission intensity near the substrate.

Figure $1 \mathrm{~b}$ : FTIR of two regions of the substrate.

It has been widely realized that ion bombardment of the substrate and growing film play a crucial role in formation of the $\mathrm{cBN}$ [3]. After determining a set of preferable conditions for BN deposition, a series of experiments was run while varying the degree of substrate ion bombardment through changing the negative substrate bias. Figure 2 shows FTIR of films deposited under five different negative substrate biases. Substrate biases up to $-90 \mathrm{~V}$ produced only hexagonal $\mathrm{BN}(\mathrm{hBN})$, while at a bias of $-110 \mathrm{~V}$ a mixture of $\mathrm{hBN}$ and $\mathrm{cBN}$ was produced. This result is consistent with that of other researchers who have observed a threshold of ion bombardment necessary for cBN deposition [3].

We are currently further examining the role of both positive and negative substrate bias in film deposition in the SPJR. The extent of the effect of a negative bias is clearly restricted to a narrow sheath in front of the substrate, thus controlling the energy of the ions impinging on the substrate. However, a positive bias affects the entire plasma between the nozzle and the substrate, including the gas phase chemistry. These effects are being investigated using a combination of Langmuir probe measurements and emission spectroscopy. 


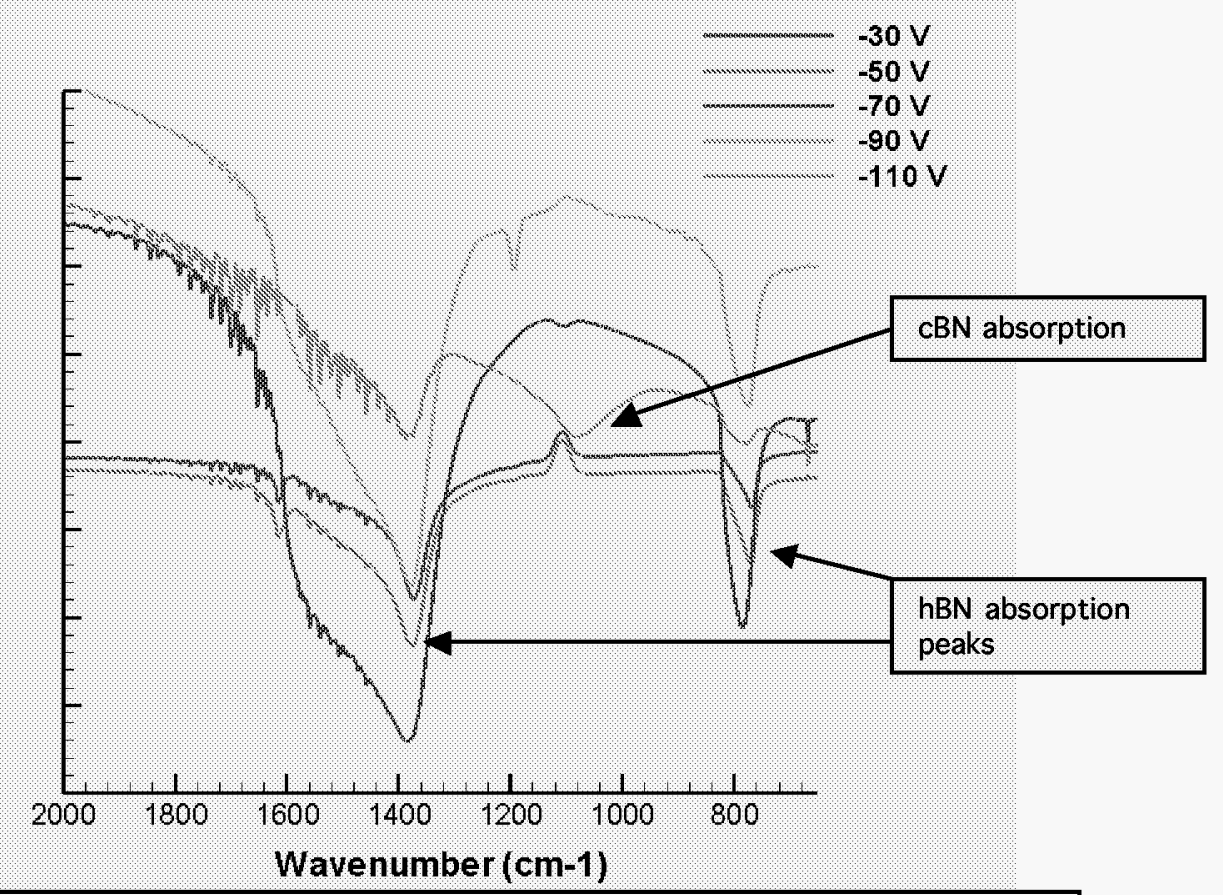

Figure 2: FTIR of 5 films deposited under different negative substrate biases.

\section{Task 2: Superhard composite films in the Triple Torch Plasma Reactor}

This task focused on investigating the novel properties associated with nanostructured materials. We studied the deposition of silicon nitride-carbon nanocomposite films including the characterization of their mechanical properties. The triple torch plasma reactor was used in a thermal plasma chemical vapor deposition process because this reactor allows injection of reactants into the region where the jets of the three torches coalesce and, therefore, provides good mixing of the reactants with the plasma. The high energy densities and rapid quench rates allow formation of nanophase materials at rapid rates.

According to thermodynamic data, an increase in the deposition temperature and/or a decrease in nitrogen partial pressure will produce a composite including silicon carbide. Since silicon carbide has a higher hardness than silicon nitride, our research has focused on incorporating silicon carbide into the silicon nitride matrix to enhance the film hardness. In addition, reaction and diffusion rates of the reactive species in the boundary layer above the substrate are being investigated to link the deposition conditions to film morphology. The fluid dynamics of the reactive region determine the boundary layer thickness, while the Damköhler number links this thickness to film morphology: 


$$
\begin{aligned}
& \mathrm{Da}=\frac{\mathrm{K} \delta^{2}}{\mathrm{D}[\mathrm{G}]} \mathrm{K}: \text { rate cons tant for gas phase reaction }\left[\mathrm{mol} / \mathrm{cm}^{3} \cdot \mathrm{sec}\right] \\
& \delta: \text { momentum boundary layer thickness }[\mathrm{cm}] \\
& \mathrm{D}: \text { gas }- \text { phase diffusion coefficient }\left[\mathrm{cm}^{2} / \mathrm{sec}\right] \\
& \mathrm{G}: \text { total gas - phase species concentration }\left[\mathrm{mol} / \mathrm{cm}^{3}\right]
\end{aligned}
$$

Our experiments are designed to achieve a kinetic-controlled process ( $\mathrm{Da}<1$ ) as it produces smoother films, which tend to provide enhanced mechanical properties. Therefore, high plasma flow rates are being used to decrease the boundary layer thickness and hence the Damköhler number.

To achieve these conditions, several modifications were made to the triple torch plasma reactor throughout the project. The experimental system was modified to include a bubbler for safe and efficient transport of the vaporized silicon-based reactant, silicon tetrachloride $\left(\mathrm{SiCl}_{4}\right)$. In addition, an isolated temperature-controlled water circuit was constructed to ensure that the $\mathrm{SiCl}_{4}$ does not condense and obstruct the path of its injection into the reaction chamber. Also, the positioning system of the three d.c. plasma torches was modified to allow for proper control of the convergence of the three plasma jets. Finally, to allow simultaneous injection of the silicon- and carbon-based reactants, an injection ring was mounted inside the reaction chamber above the chemically reactive region. This addition led to the incorporation of carbon into the silicon nitride films, increasing their hardness and elastic modulus.

Various characterization techniques were used to determine film composition, structure and hardness. Fourier transform infrared (FTIR) spectra (Figure 3) show the presence of carbon as $\mathrm{C}=\mathrm{C}, \mathrm{C}=\mathrm{N}$ and $\mathrm{C}-\mathrm{N}$ stretching modes superimposed in the band from $1100-1700 \mathrm{~cm}^{-1}$ and the $\mathrm{C} \equiv \mathrm{N}$ or $\mathrm{N}=\mathrm{C}=\mathrm{N}$ stretching mode around $2200 \mathrm{~cm}^{-1}$. Indentation analysis determined that the inclusion of carbon in the silicon nitride matrix enhanced the hardness and elastic modulus (Figure 4) as expected.

Our continuing research focuses on the production of Si-C-N nanostructured coatings exhibiting further enhanced mechanical properties. In the scope of this interest, an additional bubbler system has been constructed to deliver tetramethyldisilazane $\left(\mathrm{C}_{6} \mathrm{H}_{19} \mathrm{NSi}_{2}\right)$ to the reaction chamber. It is believed that transporting a reactant that is both silicon- and carbon-based will assist in incorporating carbon into the silicon nitride matrix. Through the continued understanding and improvement of the deposition process, nanostructured $\mathrm{Si}-\mathrm{C}$ $\mathrm{N}$ films possessing superhard properties are expected. 


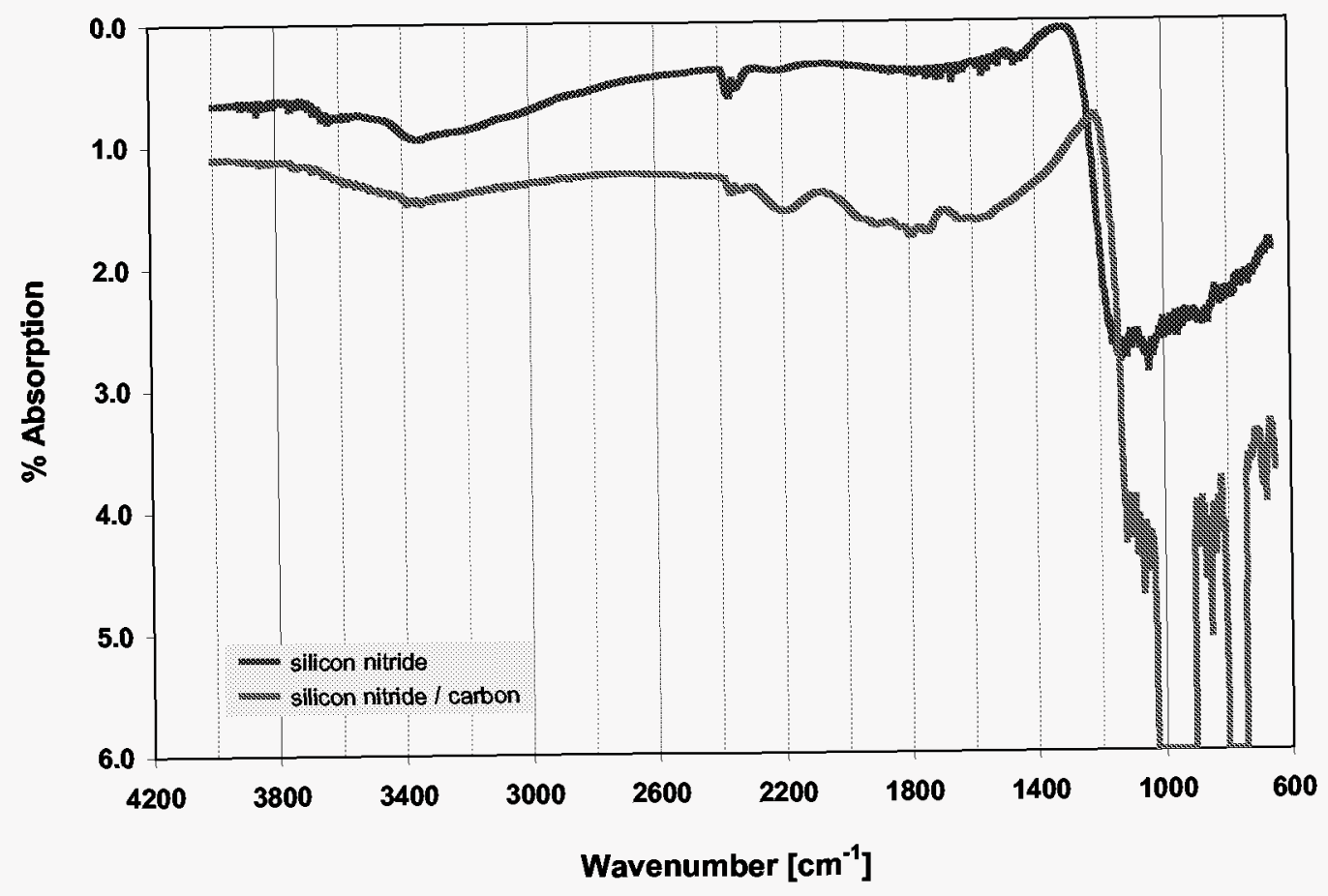

Figure 3: FTIR spectra of silicon nitride and silicon nitride-carbon films.

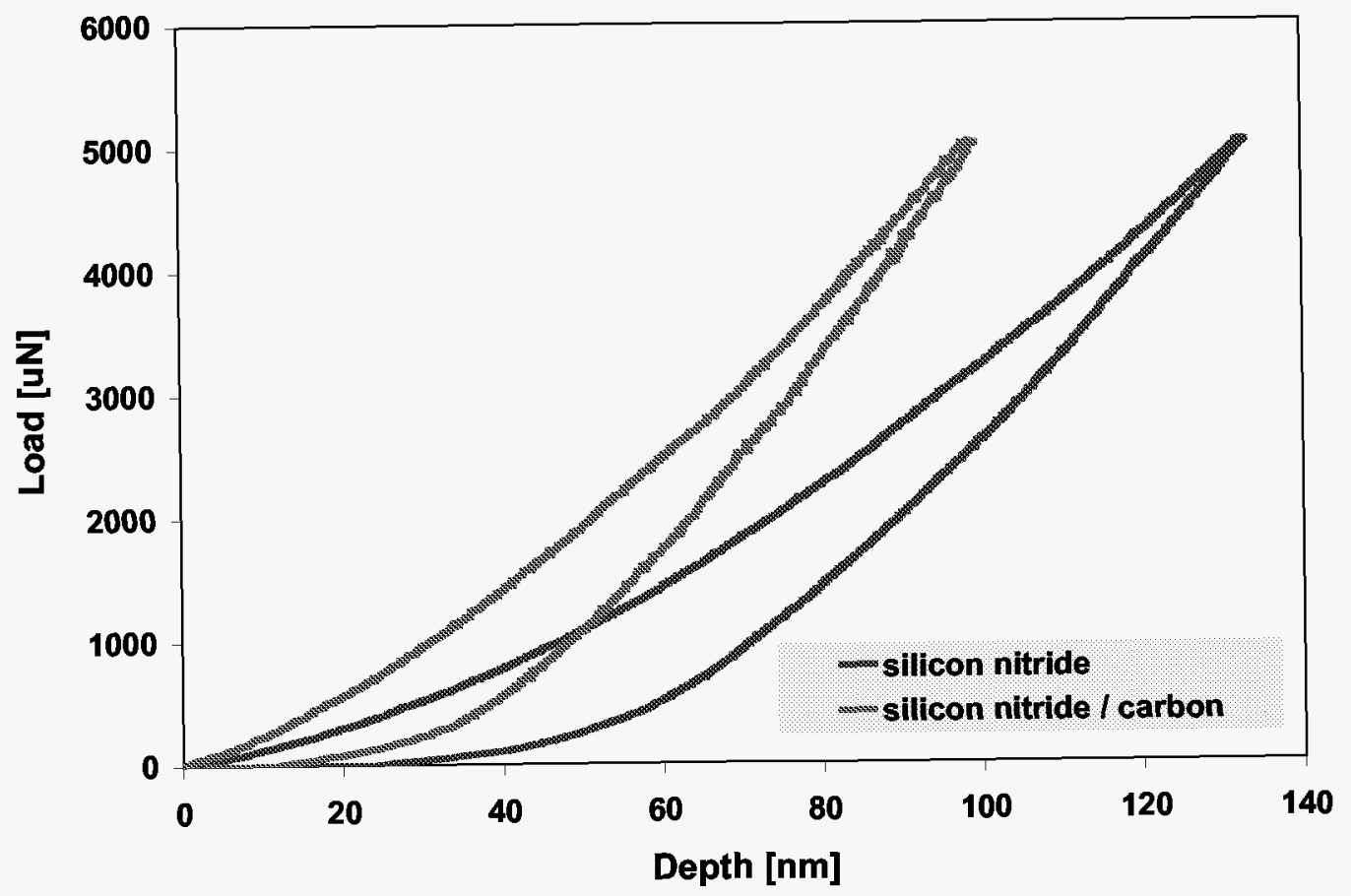

Figure 4: Nanoindentation data of silicon nitride $\left(\mathrm{H}=14.21 \mathrm{GPa}, \mathrm{E}_{\mathrm{r}}=122 . \mathrm{GPa}\right)$ and silicon nitride-carbon films $\left(\mathrm{H}=24.46 \mathrm{GPa}, \mathrm{E}_{\mathrm{r}}=180.8 \mathrm{GPa}\right)$. 


\section{Task 3: Analysis of Thomson scattering experiments in arc plasma jets}

The purpose of this task was to find ways to adapt Thomson scattering to the characterization of processing plasmas. In the literature, Thomson scattering results have been reported which contradict results obtained with other diagnostic methods, and the question was raised if the analysis technique used for evaluating the scattering data is applicable for atmospheric pressure plasmas with high gradients. Thomson laser scattering allows the simultaneous measurement of electron density and temperature if an accurate model for the fluctuations of the electron density due to interaction with the laser light is available. In the standard scattering theory the spectrum of the electron density fluctuations is described for an ideal, uniform and collisionless plasma. We will refer to this model as the random phase approximation (RPA). The RPA has then been successfully applied for measurements of electron temperature and density using Thomson scattering in several plasma environments with the exception of thermal arcs and atmospheric plasma jets. Applying the RPA model to experimental scattering spectra from thermal arc plasmas and atmospheric plasma jets yields electron temperature values that are inconsistent with values extracted from other well established diagnostics, such as emission spectroscopy or enthalpy probes. In addition, some authors have recently reported experiments showing dependence of the derived electron temperature values on the scattering angle.

Our research in this task concentrated on developing a novel technique to analyze Thomson laser light scattering data from weakly non-ideal and collisional plasmas in the presence of temperature inhomogeneities. The method we propose relies on a phenomenological description of the electron density fluctuations based on the memory function formalism (MFF) and it is shown to be more accurate than the standard random phase approximation. Indeed the results that we have obtained from our model seem to confirm that some of the problems reported in the past with Thomson scattering measurements of electron temperature and density can be avoided if the proposed approach is followed. In particular, electron temperature values obtained with this method are much less dependent on the scattering angle, with average values closer to the ones determined from spectroscopic measurements of line intensities. Figure 5 shows that both the RPA and the MFF provide excellent fits to the experimental data. However, the electron temperature values associated with these fits vary substantially (see Fig. 6). The semiempirical nature of the memory function approach allows the lumping together of several effects which may lead to inconsistencies in the RPA approach, namely collisions, non-ideality, and temperature gradients within the measurement volume. This way it has become possible to use Thomson scattering for the characterization of atmospheric pressure processing plasmas.

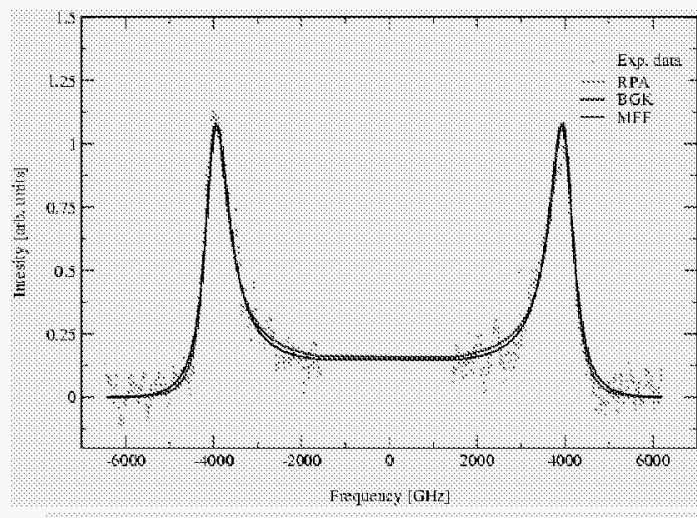

Figure 5: Experimental lineshapes obtained in an argon plasma jet compared with theoretical models. The BGK model is a modified RPA to includes weak collisionality.

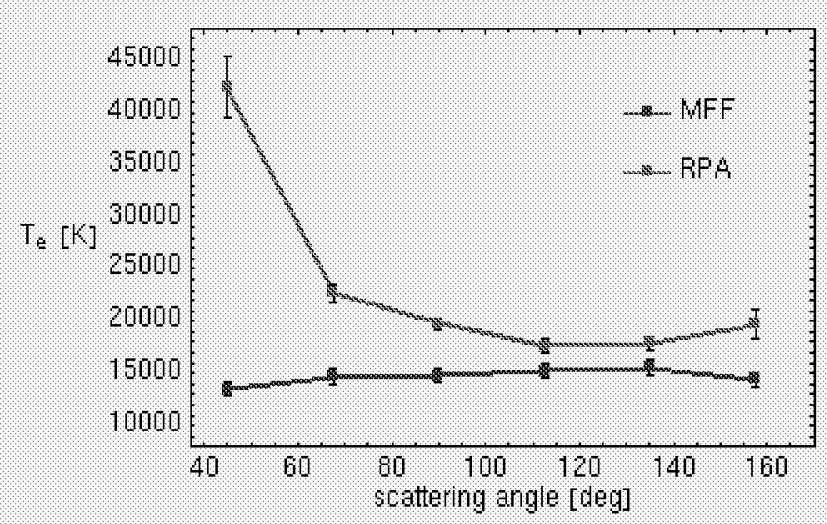

Figure 6: Average temperatures in the scattering volume measured on the axis of an argon plasma jet: RPA compared with the MFF approach. 


\section{Task 4: Nanotube films with atmospheric pressure rf discharges}

The growth of aligned carbon nanotubes has been attempted with the use of an atmospheric pressure radio frequency discharge. Our original plan was to use a dielectric barrier discharge for this deposition. However, empirical evidence indicates that the electric field in the sheath region might play a crucial role in the alignment of the nanotubes. An atmospheric pressure radio frequency $(13.56 \mathrm{MHz})$ discharge therefore gives a clear advantage with respect of the atmospheric pressure glow discharge (APG), which operates at much lower frequencies such as 10 to $100 \mathrm{kHz}$. At higher frequencies a more continuous discharge is established, so that the time-averaged electric field in the sheath is more intense. The growth rate of the nanotubes is also improved, due to a more continuous operation. Another important difference with respect of the APG is that the atmospheric pressure radio frequency discharge (APRFD) can be operated without the need of a dielectric barrier. This is explained in terms of the large and continuous ionization level in the gap, which prevents the formation of a filamentary discharge. The schematic of the experimental apparatus is given in Fig. 7.

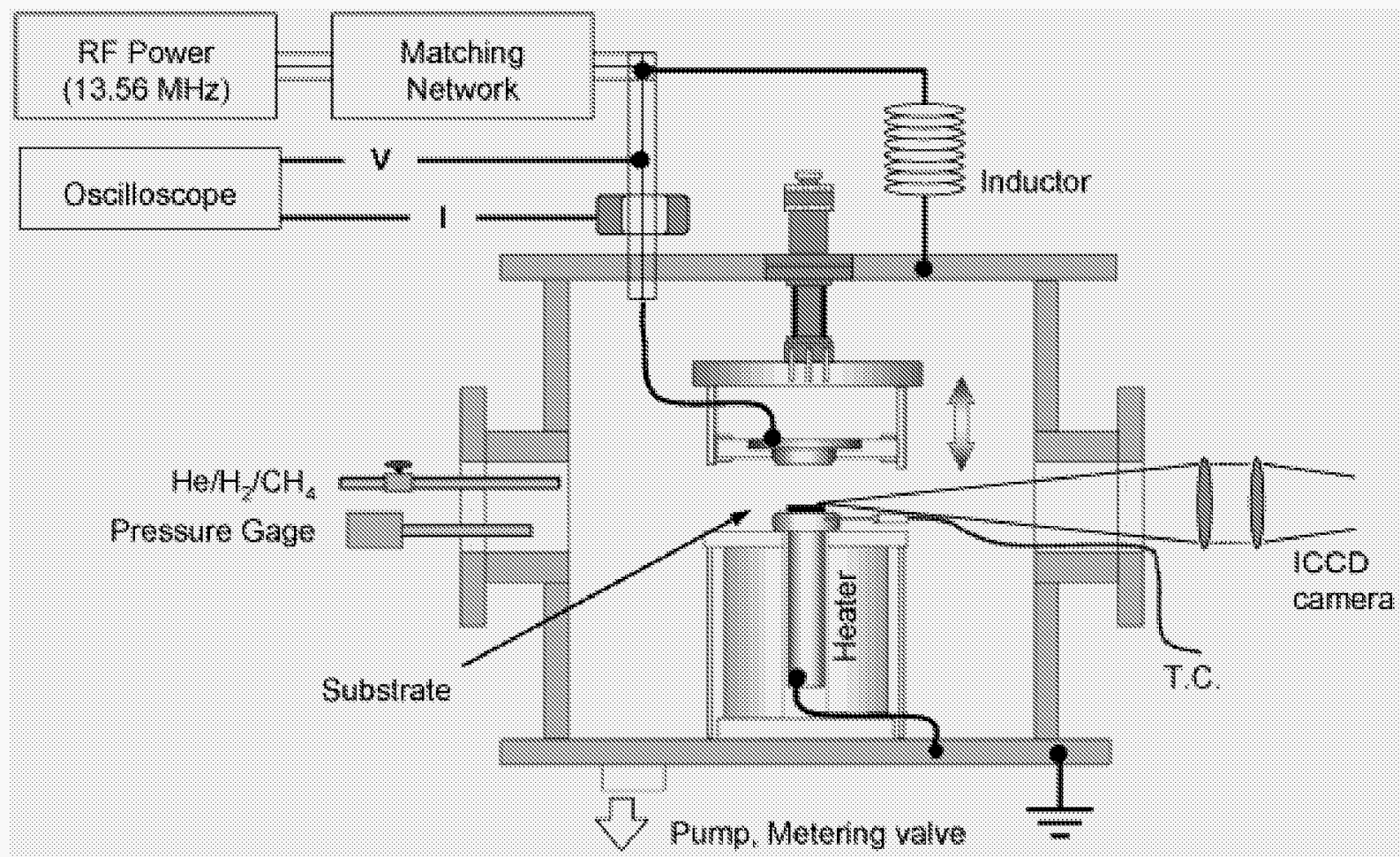

Figure 7: Schematic of the experimental apparatus for the deposition of carbon nanotubes via atmospheric pressure radio frequency discharge.

The vacuum chamber was evacuated to a pressure of $10^{-2}$ Torr before operation. It was then refilled with helium up to atmospheric pressure, and the temperature of the substrate was raised to the deposition temperature, typically $650 \mathrm{C}$. Typical operating conditions were: $2000 \mathrm{sccm} \mathrm{He}, 0-80 \mathrm{sccm} \mathrm{H}_{2}$ and $30 \mathrm{sccm} \mathrm{CH}_{4}$. The inter-electrode gap was $4 \mathrm{~mm}$. The RF power was fed to the top electrode via a matching box to maximize the 
power transferred to the load. Voltage and current waveforms were measured to determine the real power input to the discharge. This was for most experiments around $50 \mathrm{~W}$, but in some experiments the power level was increased to $125 \mathrm{~W}$. The substrate was placed on the bottom electrode, which was a stainless steel rod placed inside of a ceramic radiative heater. The substrate was composed of a Si wafer on which a $\mathrm{Cr}$ underlayer $(100 \mathrm{~nm})$ was sputtered. Subsequently a Ni layer $(20 \mathrm{~nm})$ was deposited on the surface. The substrate is pretreated in a $\mathrm{He} / \mathrm{H}_{2}$ discharge before deposition to reduce the native $\mathrm{Ni}$ oxide. An intensified fast-gated CCD camera was used to study the discharge structure during the RF cycle. A continuous emission was observed during the entire cycle, indicating that a continuous plasma was generated. Optical emission spectroscopy has been used to monitor the plasma chemistry during deposition. SEM was used to characterize the deposition. Figure 8 summarizes these results.
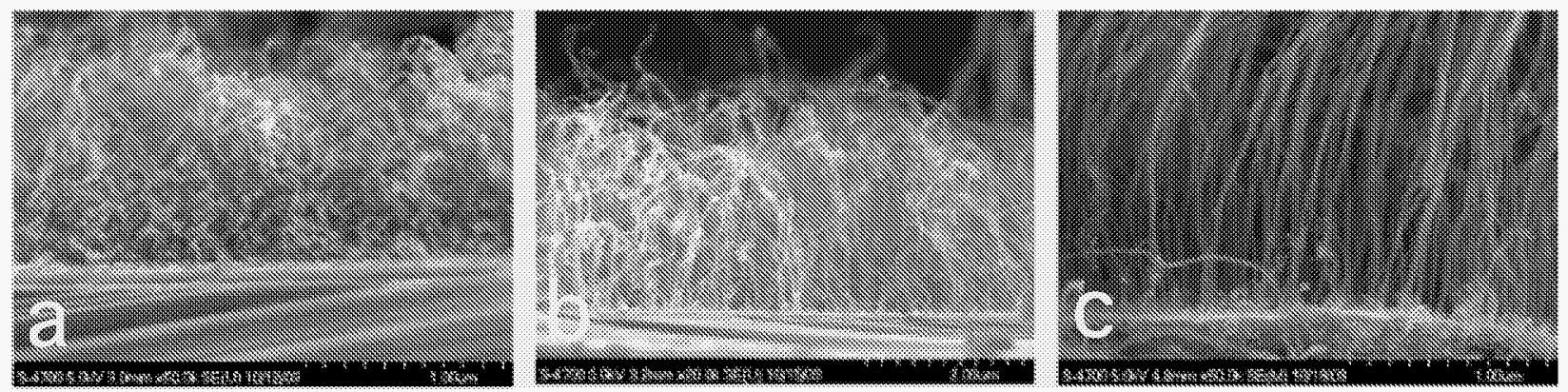

Figure 8: SEM micrographs showing the side view of the deposited nanotubes. In (a) the gas mixture was $\mathrm{He} / \mathrm{H} 2 / \mathrm{CH} 4=2000 / 0 / 100$, with $45 \mathrm{~W}$ of input power; in (b) and (c) the gas mixture was $\mathrm{He} / \mathrm{H} 2 / \mathrm{CH} 4=2000 / 60 / 30$ with $110 \mathrm{~W}$ of input power.

The growth rate was around $0.08 \mu \mathrm{m} / \mathrm{min}$ for Fig. 8a. Adding hydrogen and increasing the power input increased the growth rate to $0.2-0.5 \mu \mathrm{m} / \mathrm{min}$ (Figs. $8 \mathrm{~b}$ and c), and partially aligned nanotubes can be observed in Fig. 8c.

The higher electric field in the sheath of a APRFD can improve the alignment of the nanotubes, but many other factors play a crucial role in the morphology of the deposition. In particular, the modification of the gas mixture changes the gas phase chemistry, so it was difficult to identify the actual precursor to the nanotube growth. Also, the modification of the gas mixture changes the heat transfer of the surface, and the catalytic growth of the nanotubes was found to be very sensitive to the catalyst temperature.

Although we have succeeded in growing partially aligned nanotubes in an atmospheric pressure rf discharge at high growth rates, the strong coupling of all the parameters in this system makes a quantitative description of this process very difficult .

\section{Dissertations and other Publications}

\section{Theses:}

Gianluca Gregori, "Novel Theoretical Approaches in Thomson Laser Scattering Measurements in Weakly Nonideal, Collisional and Inhomogeneous Plasma Jets," Ph.D. Thesis, University of Minnesota, November 2001. 
Nicole Wagner, "Thermal Plasma Chemsical Vapor Deposition of Diamond and Silicon Nitride in a Triple Torch Reactor," M.S. thesis, University of Minnesota, March 2003.

Eric Runde, "Deposition of Cubic Boron Nitride Thin Films by Supersonic D.C. Plasmaenhanced Chemical Vapor Deposition." M.S. thesis, University of Minnesota, February 2004.

Lorenzo Mangolini, "Experimental and numerical study of dielectric barrier discharges in Helium," M.S. thesis, University of Minnesota, October 2002.

Two further theses are in progress:

Nicole Wagner, "Investigation of Superhard Nanostructured Coatings in the Si-C-N Ternary System," expected defense in 2006.

Jami McLaren, "Process Characterization and Deposition of Cubic Boron Nitride and other Materials from the BCN Ternary System with a Supersonic Thermal Plasma Jet Chemical Vapor Deposition Process," expected defense in 2006.

\section{Publications:}

1. J. Heberlein, O. Postel, S. Girshick, P. McMurry, W. Gerberich, D. Iordanoglou, F. Di Fonzo, D. Neumann, A. Gidwani, M. Fan and N. Tymiak, "Thermal plasma deposition of nanophase hard coatings," Surf. Coat. Technol., 142-144, pp. 265-271 (2001).

2. M. Asmann, C.F.M. Borges, J. Heberlein and E. Pfender, "The effects of substrate rotation on thermal plasma chemical vapor deposition of diamond," Surf. Coat. Technol., 142-144, pp. 724-732 (2001).

3. C.F.M. Borges, E. Pfender, J. Heberlein, "Influence of nitrided and corbonitrided interlayers on enhanced nucleation of diamond on stainless steel 304," Diamond and Related Materials, 10, pp. 1983-1990 (2001).

4. G. Gregory, U. Kortshagen, J. Heberlein, E. Pfender, "Analysis of Thomson scattered light from an arc plasma jet," Physical Review E, 65, 046411-1 to-8 (2002).

5. J. Heberlein, "New approaches in thermal plasma technology," Pure Appl. Chem., 74(3), pp. 327-335, (2002).

6. J. Heberlein and O. Postel, "Supersonic Plasma Jet Deposition of Boron Carbide/Boron Nitride Composite Films," Proc. JSPS International Symposium on Thermal Plasma Deposition, Tokyo, Japan, (2002).

7. J.V.R. Heberlein and N. Ohtake, "Plasma torch diamond deposition", in Diamond Films Handbook, edited by J. Asmussen and D.K. Reinhard (Marcel Dekker, New York; 2002) Chapter 6, pp. 141-210.

8. G. Gregori, U. Kortshagen, J. Heberlein and E. Pfender, "Novel analysis of Thomson scattering data from thermal plasma jets," Proc. 15th Intl. Conf. on Plasma Chem., 
eds. A. Bouchoule, J.M. Pouvesle, A.L. Thomann, J.M. Bauchire, E. Robert (GREMI,CNRS/Univ. of Orléans/France; July 9-13, 2001) vol. III, pp. 1091-1096.

9. E. Runde, J. McLaren and J.V.R. Heberlein, "Emission spectroscopy of a supersonic plasma jet with secondary discharge during deposition of c-BN," Proc. 16th Intl. Symp. Plasma Chem., eds. R. d'Agostino, P. Favia, F. Fracassi, F. Palumbo (Univ. of Bari, Taormina/Italy; June 22-27, 2003) p. 399.

10. G. Gregori, U. Kortshagen, E. Pfender, and J. Heberlein, "Time-resolved temperature measurements in a turbulent argon plasma jet," Proc. 16th Intl. Symp. Plasma Chem., eds. R. d'Agostino, P. Favia, F. Fracassi, F. Palumbo (Univ. of Bari, Taormina/Italy; June 22-27, 2003) p. 640.

11. Tomohiro Nozaki, Ken Okazaki, Lorenzo Mangolini, Joachim Heberlein, and Uwe Kortshagen, "Atmospheric Pressure Radio-Frequency Discharge and its Application to Carbon Nanotube Growth," Proc. Hakone IX International Symposium on Plasma Chemistry (August 23-27 2004, Padova, Italy).

\section{Unpublished presentations at conferences acknowledging DOE support:}

1. N.J. Wagner, D. Bendix, J.V.R. Heberlein, "Chemical vapor deposition of superhard nanocomposites in a triple torch plasma reactor," Proc. 55th Annual Gaseous Electronics Conference, Minneapolis, Minnesota, October 15-18, 2002, pp.59-60.

2. N.J. Wagner, T. Nozaki, J.V.R. Heberlein, "Thermal plasma chemical vapor deposition of nanostructured silicon nitride in a triple torch reactor," International Workshop on Nanoparticle Science and Engineering, Minneapolis, Minnesota, July 17-18, 2003 , p.30.

3. N.J. Wagner, T. Nozaki, J.V.R. Heberlein, "Thermal plasma chemical vapor deposition of nanostructured silicon nitride-carbon in a triple torch reactor," 7th International Conference on Nanostructured Materials, Wiesbaden, Germany, June 20-24, 2004, p.329.

4. N.J. Wagner, T. Nozaki, J.V.R. Heberlein, "Thermal plasma chemical vapor deposition of nanostructured silicon nitride-carbon in a triple torch reactor," International Workshop on Nanoparticles: Synthesis, Characterization and Properties, Duisburg, Germany, June 25- 26, 2004, p.P11.

5. J. McLaren, L. Zajickova, J. Heberlein, "Characterization of a Thermal Plasma Cubic Boron Nitride Deposition Process," Gordon Conference on Plasma Processing Science, Plymouth, NH, August 15 - 20, 2004.

6. L. Zajickova, N. Wagner, M. Cordill, T. Nozaki, J. Heberlein, "Plasma Enhanced CVD of Silicon Nitride/Carbon Based Hard Films in a Triple Torch Reactor," Gordon Conference on Plasma Processing Science, Plymouth, NH, August 15 - 20, 2004.

7. N.J. Wagner, M. Cordill, L. Zajickova, J.V.R. Heberlein, W.W. Gerberich, "Thermal plasma chemical vapor deposition of superhard nanostructured Si-C-N coatings," Materials Research Society Spring Meeting, San Francisco, California, March 28April 1, 2005, p.BB2.10/O3.10. 


\section{References}

[1]. W. Kalss, R. Haubner, and B. Lux. Diamond and Related Materials, Vol. 7, 1998, 369-75.

[2]. E. Runde. "Deposition of Cubic Boron Nitride Thin Films by Supersonic D.C. Plasma-enhanced Chemical Vapor Deposition." Masters' thesis, University of Minnesota, 2004.

[3]. T. Yoshida . Diamond and Related Materials, Vol. 5, 1996, 501-07.

[4]. E. Runde, J. McLaren, J. Heberlein. "Optical Emission Spectroscopy of a Supersonic DC Plasma Jet for Deposition of BN Films." Proceedings of the $16^{\text {th }}$ International Symposium on Plasma Chemistry (2003). 